\title{
Fruit ripening-associated leucylaminopeptidase with cysteinylglycine dipeptidase activity from durian suggests its involvement in glutathione recycling
}

Pawinee Panpetch ${ }^{1}$ and Supaart Sirikantaramas ${ }^{1,2^{*}}$

\begin{abstract}
Background: Durian (Durio zibethinus L.) is a highly popular fruit in Thailand and several other Southeast Asian countries. It is abundant in essential nutrients and sulphur-containing compounds such as glutathione (GSH) and $\gamma^{-}$ glutamylcysteine ( $\gamma-\mathrm{EC}$ ). Cysteinylglycine (Cys-Gly) is produced by GSH catabolism and occurs in durian fruit pulp. Cysteine (Cys) is a precursor of sulphur-containing volatiles generated during fruit ripening. The aforementioned substances contribute to the strong odour and flavour of the ripe fruit. However, the genes encoding plant Cys-Gly dipeptidases are unknown. The aim of this study was to measure leucylaminopeptidase (LAP) activity in durian fruit pulp.

Results: We identified DzLAP1 and DzLAP2, which the former was highly expressed in the fruit pulp. DzLAP1 was expressed at various ripening stages and in response to ethephon/1-MCP treatment. Hence, DzLAP1 is active at the early stages of fruit ripening. DzLAP1 is a metalloenzyme $\sim 63 \mathrm{kDa}$ in size. It is activated by $\mathrm{Mg}^{2+}$ or $\mathrm{Mn}^{2+}$ and, like other LAPs, its optimal alkaline $\mathrm{pH}$ is 9.5. Kinetic studies revealed that DzLAP1 has $\mathrm{K}_{\mathrm{m}}=1.62 \mathrm{mM}$ for its preferred substrate Cys-Gly. DzLAP1-GFP was localised to the cytosol and targeted the plastids. In planta Cys-Gly hydrolysis was confirmed for Nicotiana benthamiana leaves co-infiltrated with Cys-Gly and expressing DzLAP1.
\end{abstract}

Conclusions: DzLAP1 has Cys-Gly dipeptidase activity in the $\gamma$-glutamyl cycle. The present study revealed that the LAPs account for the high sulphur-containing compound levels identified in fully ripened durian fruit pulp.

Keywords: Cys-Gly, Durian, Fruit ripening, LAP, Leucylaminopeptidase, Sulphur compound

\footnotetext{
*Correspondence: supaart.s@chula.ac.th

${ }^{1}$ Molecular Crop Research Unit, Department of Biochemistry, Faculty of Science, Chulalongkorn University, 254 Phayathai Road, Bangkok 10330, Thailand

${ }^{2}$ Omics Sciences and Bioinformatics Centre, Chulalongkorn University, 254

Phayathai Road, Bangkok 10330, Thailand
}

(c) The Author(s). 2021 Open Access This article is licensed under a Creative Commons Attribution 4.0 International License, which permits use, sharing, adaptation, distribution and reproduction in any medium or format, as long as you give appropriate credit to the original author(s) and the source, provide a link to the Creative Commons licence, and indicate if changes were made. The images or other third party material in this article are included in the article's Creative Commons licence, unless indicated otherwise in a credit line to the material. If material is not included in the article's Creative Commons licence and your intended use is not permitted by statutory regulation or exceeds the permitted use, you will need to obtain permission directly from the copyright holder. To view a copy of this licence, visit http://creativecommons.org/licenses/by/4.0/ The Creative Commons Public Domain Dedication waiver (http://creativecommons.org/publicdomain/zero/1.0/) applies to the data made available in this article, unless otherwise stated in a credit line to the data. 


\section{Key message}

DzLAP1 characterisation in durian (Durio zibethinus L.) fruit pulp indicated that it participates in cysteinylglycine degradation and glutathione recycling during ripening.

\section{Background}

Durian (Durio zibethinus L.) is a highly flavourful fruit grown in Thailand and other Southeast Asian countries. Fresh durian production and export are highly profitable. Several studies showed that durian is rich in protein, carbohydrate, fat [1], and bioactive phenolic and anti-proliferative compounds [2-4]. Durian fruit has unique texture, flavour, and odour. During ripening, the sulphur-containing volatile-associated gene methionine $\gamma$-lyase $(M G L)$ and the ethylene-related gene aminocyclopropane-1-carboxylic acid synthase $(A C S)$ are upregulated. Correspondingly, their respective metabolites (sulphur volatiles and ethylene) accumulate. Hence, there is a correlation between ethylene biosynthesis and sulphur volatile production during ripening [5]. After the publication of the draft durian genome in 2017 [5], our group identified several transcription factors associated with ripening process. For example, DzDof2.2 is involved in the regulation of auxin biosynthesis [6] and DzARF2A could bind to the promoters of several ethylene biosynthetic genes and, thus, controls durian fruit ripening [7].

Several sulphur-containing volatiles are responsible for the pungent odour of ripe durian fruit. Glutathione (GSH), gamma-glutamylcysteine $(\gamma$-EC), $S$-adenosylmethionine (SAM), cysteine (Cys), and cysteinylglycine (Cys-Gly) were detected in the ripe fruit pulp of the Thai cultivars Chanee and Monthong [8]. The former has a stronger odour and faster postharvest ripening than the latter. Moreover, ripe Chanee fruit has higher Cys and Cys-Gly levels than ripe Monthong fruit [8].

Cys-Gly is an important intermediate in the $\gamma$ glutamyl cycle of sulphur metabolism. It participates in redox homeostasis and recycles amino acids in living cells. In mammals, Cys-Gly is the product of GSH degradation via sequential $\gamma$-glutamyl transpeptidase (GGT), $\gamma$-glutamyl cyclotransferase (GGCT), and 5-oxoprolinase (OPase) reactions [9]. Nevertheless, only the concerted actions of GGCT and OPase or a GGT-independent pathway governed Cys-Gly production in Arabidopsis [10]. Cys-Gly is hydrolysed to Cys and Gly by a dipeptidase. Cys-Gly is a pro-oxidant and may contribute to the intracellular redox environment. Excess Cys-Gly was toxic to yeast cells $[11,12]$. Therefore, enzymatic CysGly regulation may be vital. Moreover, the release of Cys is important as this amino acid can be converted to methionine used in sulphur volatile production during fruit ripening [5].
Leucylaminopeptidases (LAPs, EC. 3.4.11.1) are members of the M17 enzyme family. They might process intracellular proteins but their precise metabolic functions are still unknown. They preferentially hydrolyse Cys-Gly in Bos taurus (cow) [13], Treponema denticola [14], and Arabidopsis [15]. They were originally named LAPs as early reports suggested that they react with $N$ terminal leucines [16]. The cytosolic M20 metallopeptidase Dug1p has Cys-Gly peptidase activity. Its homologues occur in mammals and yeast but not plants [17]. LAPs have six identical monomers comprising two conserved Zn-binding sites per subunit [18]. They all participate in amino acid turnover but their other biological functions are complex and species-specific. Escherichia coli LAP, also known as XerB, PepA, or CarP, is an aminopeptidase-independent DNA-binding protein $[19,20]$. It mediates site-specific plasmid and phage recombination $[21,22]$ and activates transcriptional $\operatorname{car} A B$ operons [20]. Multiple functions have been reported for mammalian LAPs. Interferon- $\gamma$ (IFN- $\gamma$ ) induction promoted high LAP accumulation. LAP may participate in antigen presentation in humans [23, 24]. Animal LAPs have been implicated in oxidative lens aging [25]. Plant LAP-A is a defence protein that plays important roles in floral development in Solanaceae [26-29].

Plant LAPs are either acidic LAP-A or neutral LAP-N depending on their pI. LAP-A and LAP-N have distinct biochemical properties and respond differently to developmental and environmental cues. LAP-A occurs only in the Solanaceae, is induced by biotic and abiotic stress [30-32], and accumulates in reproductive organs [33, 34]. In contrast, LAP-N is constitutively produced in all plants [32, 34]. $L A P$-A-silenced tomatoes were relatively more susceptible to Manduca sexta (tomato hornworm) invasion than their wild type counterparts [35]. LAP-A and LAP-N are molecular chaperones protecting proteins from heat damage [36]. Here, we identified two LAP isoforms in durian fruit pulp. Of these, the LAP-N DzLAP was highly expressed in the pulp. We biochemically characterised DzLAP1 expressed as a His-tagged protein in E. coli. Our objective was to clarify its cooperative function in sulphur-volatile production via Cys liberation from CysGly cleavage. We discovered that DzLAP1 was localised to both the cytoplasm and chloroplast. We examined its physiological roles in cytosolic GSH and plastidial peptide catabolism. To the best of our knowledge, the present work is the first to report the involvement of LAPs and associate DzLAP1 with durian fruit ripening.

\section{Results}

LAP identification, protein sequence alignment, and phylogenetic analysis

According to the open-source Musang King durian cultivar genome database, DzLAP1_MK and DzLAP2_MK 
were identified. Only one Chanee $D z L A P$ isoform was present in the in-house RNA-seq data obtained from ripe fruit pulp tissues (data not shown). Full-length Chanee DzLAP was aligned with the LAPs of Musang King and tomato (Solanum lycopersicum; SILAP1 and SlLAP2), potato (Solanum tuberosum; StLAP1 and StLAP2), and Arabidopsis (Arabidopsis thaliana; AtLAP1 to AtLAP3). The putative Chanee DzLAP was annotated as DzLAP1 (accession no. MN879753) and encoded DzLAP1. It was represented as DzLAP1_CN in multiple alignment and phylogenetic neighbour-joining (N)). DzLAP1_CN clustered with Musang King DzLAP1_MK. DzLAP1 shared 99.3 and 89.7\% identity with DzLAP1_MK and DzLAP2_MK, respectively. The essentially high \% identity between DzLAP1 and DzLAP1_MK is possibly resulted from the SNP present among different cultivars. There were eight highly conserved residues (K350, D355, K362, D375, D435, E437, R439, and L463 of DzLAP1) involved in substrate binding or catalytic function (Fig. 1, arrowheads). Five

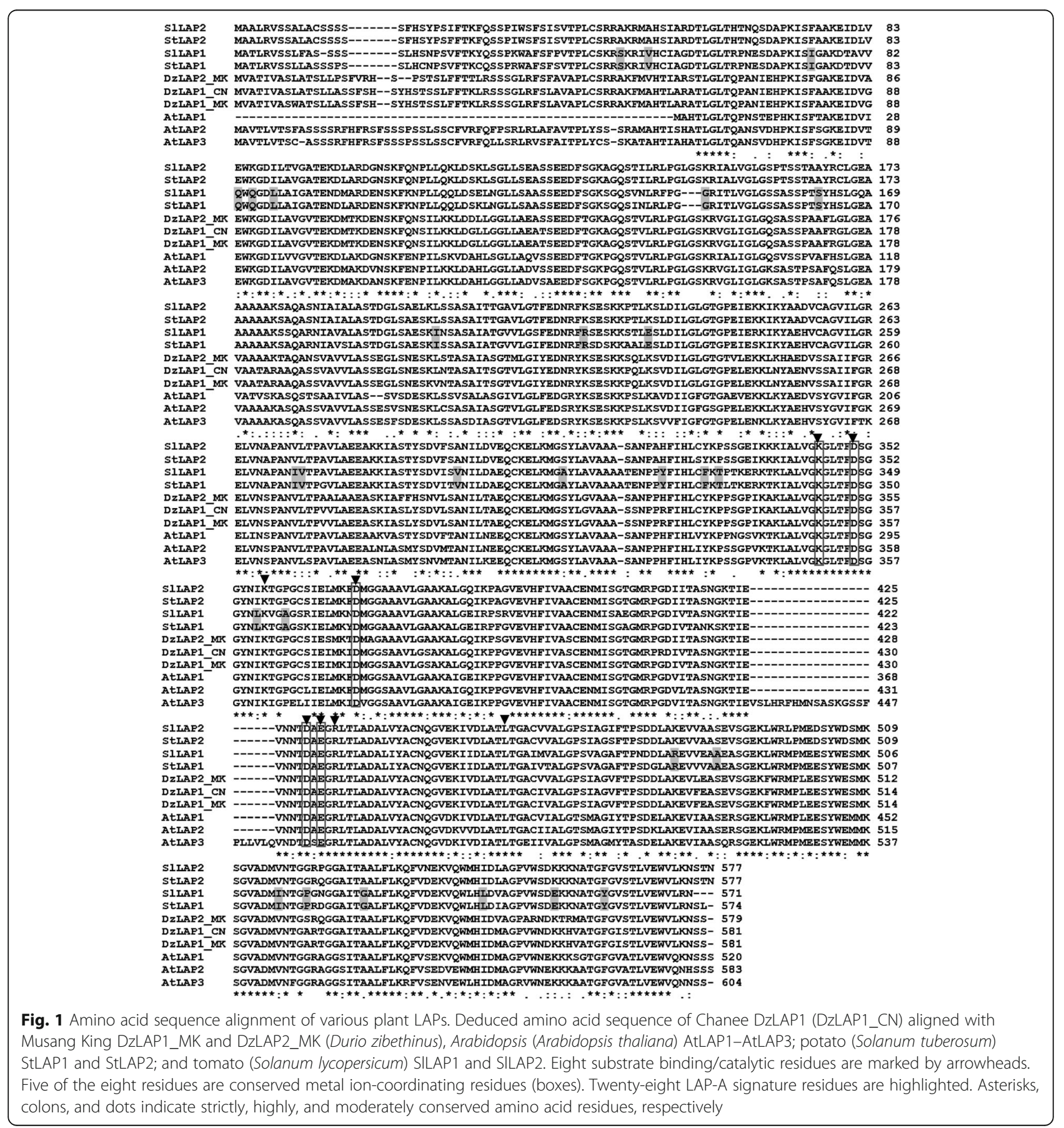


conserved residues (K350, D355, D375, D435, and E437) interacted with metal ions $[37,38]$ which are vital enzyme cofactors. These conserved residues comprise a subset of the catalytic residues (Fig. 1, boxes). All protein sequences including DzLAP1 but neither SILAP1 nor StLAP1 harboured substitutions of all 28 LAP-A signature residues (Fig. 1, highlights). Fully conserved residues were detected in the $C$-terminal region containing all essential active residues participating in catalysis (Fig. 1, asterisks). In contrast, the $N$-terminal region harboured highly variable amino acid sequences [34]. AtLAP1 lacked the signal peptide sequence but the $N$-terminal regions of SILAPs and StLAPs were slightly shorter than the other sequences. Only 64-77\% identity was established when comparing two isoforms of both SILAP and StLAP with two and three isoforms of DzLAP_MK and AtLAP, respectively.

A phylogenetic analysis revealed that all plant LAPs clustered together and were separate from those of bacteria (Fig. 2). However, Cys-Gly peptidase activity was detected in certain plant and bacterial LAPs. Tomato SlLAPs and potato StLAPs were separate from those of Arabidopsis and durian and participated in defence responses and protein catabolism (Fig. 2). In contrast, they had little activity towards Cys-Gly [30]. Various LAPs resided in different cellular compartments and may have had divergent putative functions (Fig. 2).

\section{Gene expression analysis by qRT-PCR}

In silico analysis disclosed that $D z L A P \_M K$ expression substantially varied among tissue types. $D z L A P 1 \_M K$ expression was highest in durian pulp whereas $D z L A P 2$ 2 $M K$ was expressed in other tissues (Supplementary Fig. S1). Hence, we focused on DzLAP1_MK as it was nearly identical to Chanee DzLAP1. The qRT-PCR revealed differential DzLAP1 expression at the unripe, midripe, and ripe stages of Chanee and Monthong fruit pulp. DzLAP1 was significantly upregulated from the unripe to midripe stages but downregulated by the ripe stage (Fig. 3a). DzLAP1 expression in the Chanee cultivar (white bars) somewhat resembled that in the Monthong cultivar (black bars) (Fig. 3a). The phytohormones ethephon and 1-MCP were applied to validate the association between $D z L A P 1$ and fruit ripening. DzLAP1 was significantly downregulated in the fruit pulp treated with $1-\mathrm{MCP}$ compared to the fruit pulp undergoing natural ripening (control) or treated with the ripening agent ethephon (Fig. 3b). However, ethephon treatment had relatively little influence on $D z L A P 1$ expression.

\section{In planta Cys-Gly dipeptidase activity analysis}

Cys-Gly dipeptidase activity was assessed for crude fruit pulp extracts at the unripe and midripe stages (Supplementary Fig. S3). Cys-Gly dipeptidase activity was significantly higher in the midripe (white bars) than the unripe (black bars) sample $(p<0.05)$. This finding was consistent with that obtained from the gene expression analysis (Fig. 3a). Cys-Gly dipeptidase activity was also confirmed for Nicotiana benthamiana leaves coinfiltrated with $15 \mathrm{mM}$ Cys-Gly and harbouring either

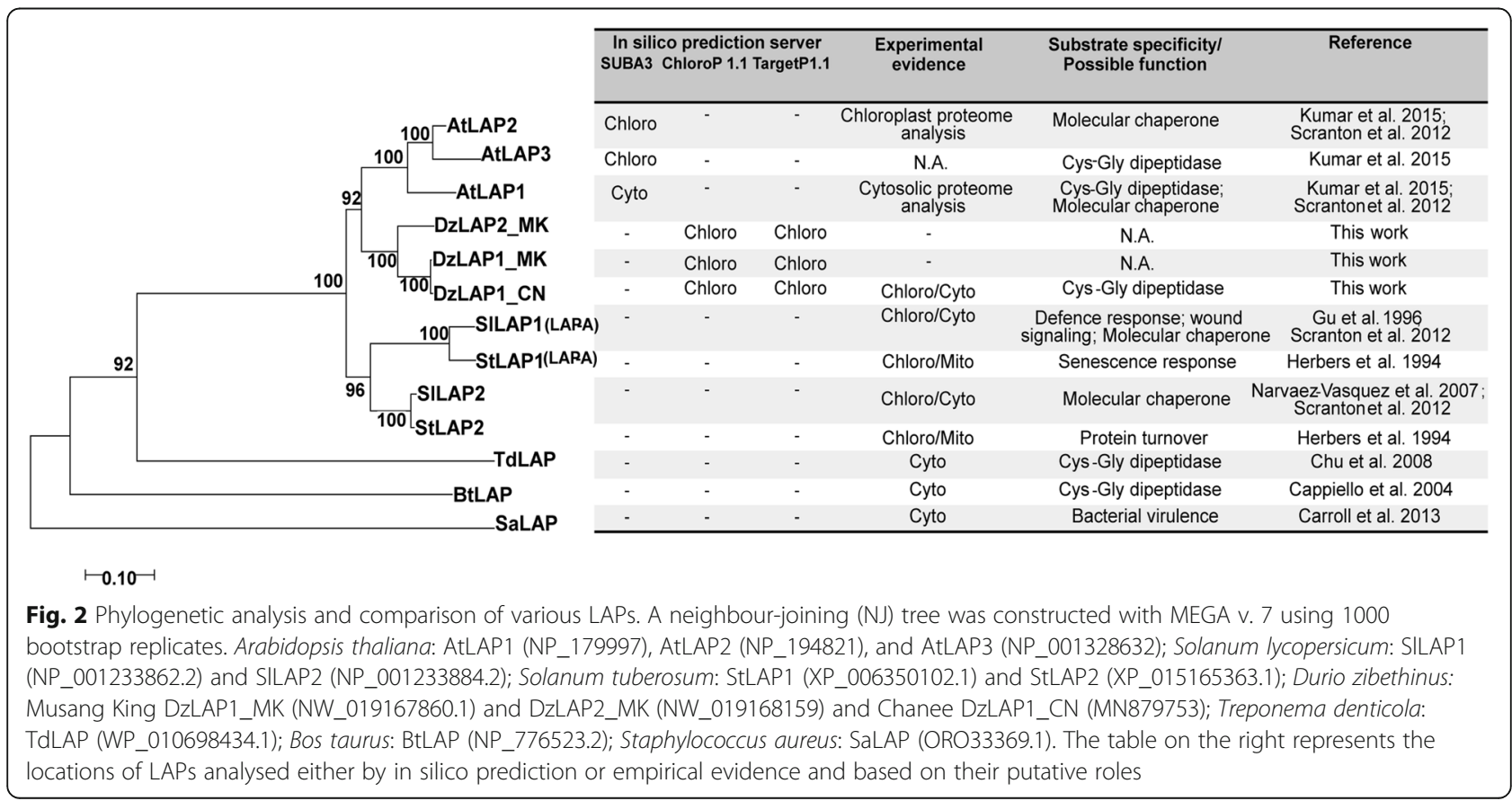




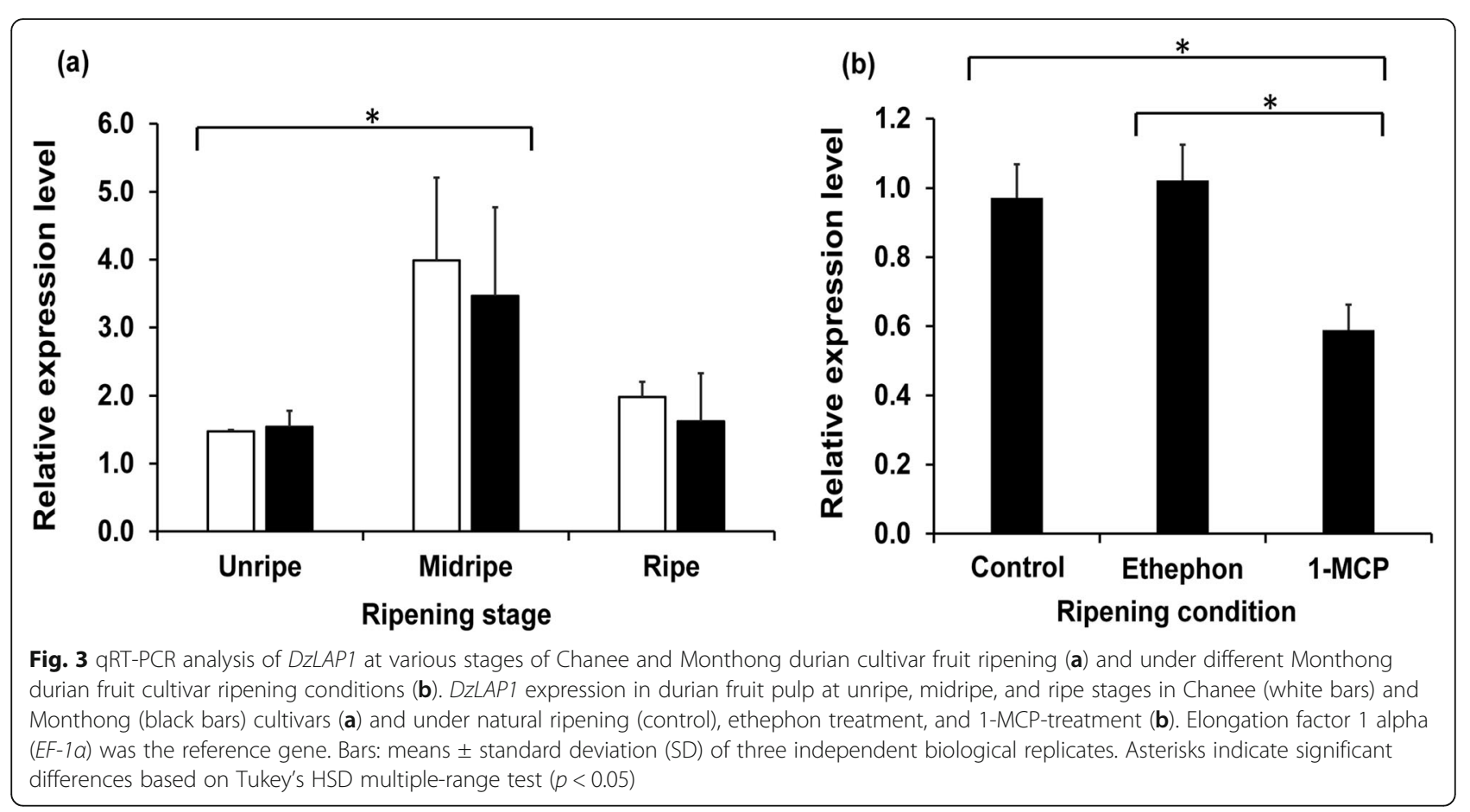

pEAQ-DzLAP1 or pEAQ (control). The leaves were collected and their Cys-Gly levels were quantified by HPLC. The Cys-Gly was significantly higher in the control than the DzLAP1-overexpressing leaves $(p<0.05)$ (Fig. 4).

\section{In vitro rDzLAP1 production and biochemical characterisation}

Purified soluble rDzLAP1 produced by E. coli appeared as a single-band protein on SDS gel. Its molecular weight was $\sim 63 \mathrm{kDa}$ and was confirmed by western blot (Fig. 5a). Relative to the BSA standard, the purified DzLAP1 concentration was $\sim 1.16 \mathrm{mg} \mathrm{mL}^{-1}$.

The metalloenzyme activity of DzLAP1 was tested by incubating the enzyme with Cys-Gly substrate in the presence of $\mathrm{Ca}^{2+}, \mathrm{Zn}^{2+}, \mathrm{Mg}^{2+}, \mathrm{Ni}^{2+}$, and $\mathrm{Mn}^{2+}$. DzLAP1 activity was measured by a modified acidic ninhydrin method detecting released cysteines are detected. The highest DzLAP1 activity was obtained when the reaction systems contained $\mathrm{Mg}^{2+}$ and $\mathrm{Mn}^{2+}$. Conversely, $\mathrm{Ca}^{2+}$, $\mathrm{Zn}^{2+}$, and $\mathrm{Ni}^{2+}$ had minimal effect as DzLAP1 activity in their presence did not significantly differ from that measured for the metal ion-free control (Fig. 5b). $\mathrm{Mg}^{2+}$ was selected as the DzLAP1 cofactor in the enzyme kinetics assay. Optimal DzLAP1 pH was established by incubating the enzyme with Cys-Gly at pH4.0-11.0. DzLAP1 had maximum activity against Cys-Gly at $\mathrm{pH}$ 9.5 (Fig. $5 \mathrm{c}$ ) and $\sim 80 \%$ of the enzyme activity occurred in a $\mathrm{pH}$ range of 8.0-11.0. At $\mathrm{pH}<7.0$, DzLAP1 activity was $<50 \%$ and at $\mathrm{pH} 4.0-5.0$, the enzyme was inactive.

To identify enzyme substrate specificity, $3.5 \mu \mathrm{g}$ purified rDzLAP1 was incubated with various substrate

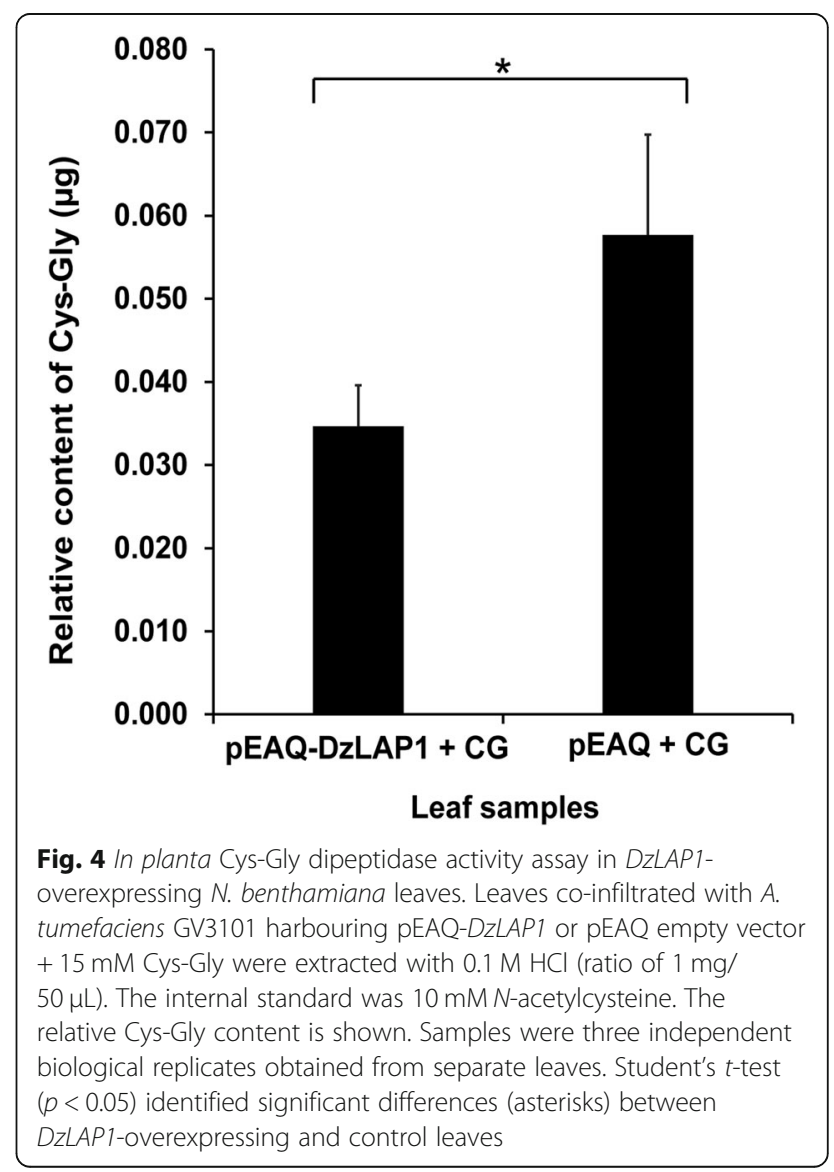




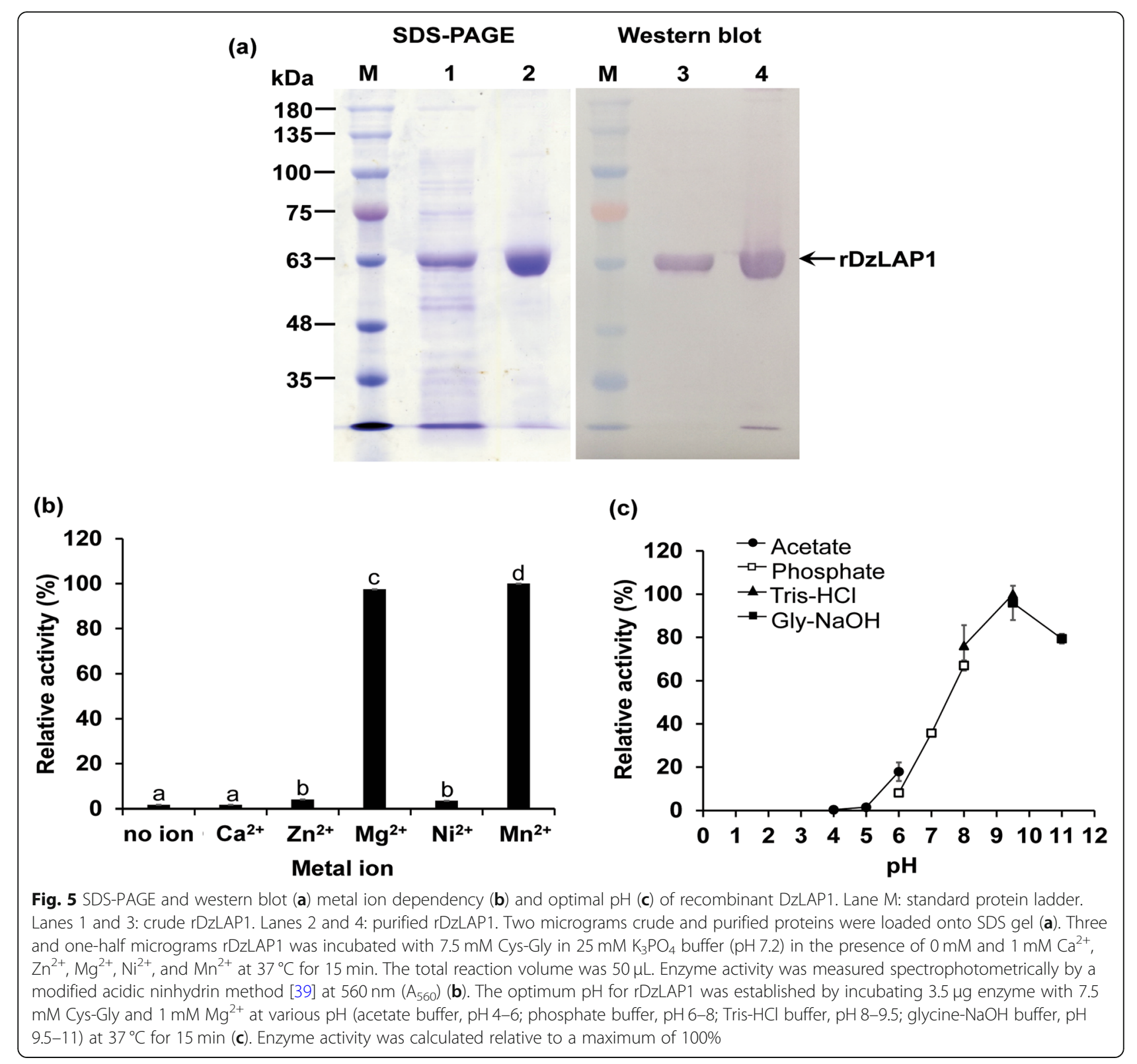

concentrations in the presence of $1 \mathrm{mM} \mathrm{MgCl} 2+25 \mathrm{mM}$ $\mathrm{K}_{3} \mathrm{PO}_{4}$ buffer ( $\mathrm{pH} 8.0$ ) at $37^{\circ} \mathrm{C}$ for a specific length of time. There was no DzLAP1 activity in the presence of GSH or $\gamma$-Glu-Cys (Table 1). DzLAP1 had positive activity against various $\alpha$-linked dipeptides. Therefore, it was proposed that this enzyme is a Cys-Gly dipeptidase as it

Table 1 DzLAP1 kinetics on different substrates

\begin{tabular}{llll}
\hline Substrate & $\boldsymbol{k}_{\text {cat }}\left(\mathbf{m i n}^{-1}\right)$ & $\mathbf{K}_{\mathbf{m}}(\mathbf{m M})$ & $\boldsymbol{k}_{\text {cat }} / \mathbf{K}_{\mathbf{m}}\left(\mathbf{m i n}^{-1} \mathbf{m m}^{-1}\right)$ \\
\hline GSH & N.D. & N.D. & N.D. \\
Y-Glu-Cys & N.D. & N.D. & N.D. \\
Cys-Gly & $74.8 \pm 8.1$ & $1.6 \pm 0.3$ & 46.2 \\
Met-Gly & $2.1 \pm 0.4$ & $5.2 \pm 1.3$ & 0.4 \\
Leu-Gly & $2.9 \pm 0.4$ & $0.4 \pm 0.1$ & 8.2 \\
\hline
\end{tabular}

had maximum catalytic efficiency in the presence of Cys-Gly. The $k_{\text {cat }} / \mathrm{K}_{\mathrm{m}}$ for Cys-Gly was $\sim 118 \times$ and $\sim 6 \times$ higher than those for Met-Gly and Leu-Gly, respectively (Table 1). However, a previous report indicated that LAP preferred $\mathrm{N}$-terminal Leu peptides and had high affinity for Leu-Gly $\left(\mathrm{K}_{\mathrm{m}}=0.35 \mathrm{mM}\right)$ [30].

\section{Subcellular DzLAP1 localisation in $N$. benthamiana}

An in silico analysis predicted that DzLAP1 is a chloroplast-localised protein. The pGWB5-DzLAP1 and the silencing suppressor $p 19$ were co-expressed in Agrobacterium tumefaciens GV3101 infiltrated in 4-wk $N$. benthamiana leaves. The in planta assay showed that GFP-tagged DzLAP1 was a soluble protein probably localised to the cytosol (Fig. 6). Fluorescence signals 


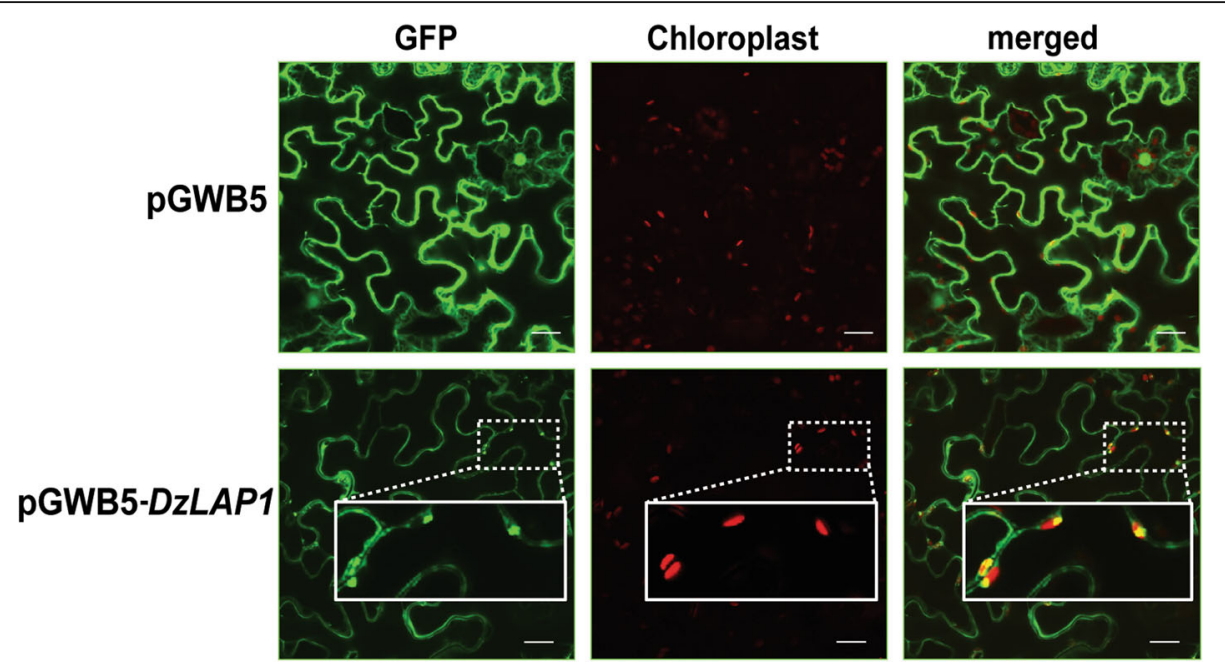

Fig. 6 Subcellular GFP-tagged DzLAP1 localisation in Nicotiana benthamiana leaves. Confocal microscopic images of N. benthamiana leaf epidermal cells infiltrated with pGWB5 (control; upper panel) and pGWB5-DzLAP1 (lower panel). GFP fluorescence (GFP), chloroplast autofluorescence (chloroplast), and merged images are shown. Plastidial DzLAP1-GFP localisation is shown as enlargements in the insets. Scale bars: $20 \mu \mathrm{m}$

were detected in the chloroplasts (Fig. 6, insets). Hence, durian DzLAP1 may be localised either to cytosol or the chloroplasts.

\section{Discussion}

Durian fruit pulp accumulates large quantities of GSH [8] which is vital for plant cell homoeostasis [40] and stores Cys via incorporation with Glu and Gly in the $\gamma$ glutamyl cycle [41]. Cys is recycled from the hydrolysis of Cys-Gly which is a by-product of GSH breakdown. This mechanism may generate abundant ethylene precursors and sulphur-volatile compounds via Met synthesis. Both pathways promote durian fruit ripening and the malodour associated with it. Cys-Gly was detected in durian fruit pulp [8]. Hence, the $\gamma$ glutamyl cycle must be activated in durian fruit ripening. In the present study, we aimed to identify and characterise the DzLAPs involved in the aforementioned biochemical processes. There has been little published information on the involvement of Cys-Gly dipeptidase in the $\gamma$-glutamyl cycle $[15,17]$.

LAPs are highly conserved metallopeptidases in animals, plants, and microorganisms [42]. Several LAPs were identified in Arabidopsis [15] and durian (this work). Arabidopsis has three LAPs encoding AtLAP1AtLAP3. DzLAP1_MK and DzLAP2_MK were detected in the durian cultivar Musang King genome [5]. We focused on DzLAP1_MK as it was highly expressed in durian fruit pulp (Supplementary Fig. S1) and GSH and $\gamma$-EC accumulated there [8]. DzLAP1_MK showed 99.3\% identity with DzLAP1 in the durian cultivar Chanee. DzLAP1 was the only isoform detected in our in-house
RNA-seq data. A primary protein sequence analysis (Fig. 1) confirmed that DzLAP1 is LAP-N as it contains the conserved substrate binding, catalytic, and metal ionbinding residues associated with the enzyme mechanism.

Postharvest DzLAP1 expression analyses showed upregulation at the midripe stage. Thus, DzLAP1 may hydrolyse Cys-Gly to Cys and Gly and cause the strong malodour associated with durian fruit pulp ripening. Relative DzLAP1 expression was similar for Chanee and Monthong at all ripening stages (Fig. 3a). However, the Cys-Gly content was significantly higher in Chanee than Monthong $(p<0.01)$ [8]. Therefore, DzLAP1 is not cultivar-dependent and does not account for the relative differences between Chanee and Monthong in terms of fruit odour intensity. The competitive ethylene inhibitor 1 -MCP significantly repressed DzLAP1 during postharvest ripening $(p<0.05)$ (Fig. $3 \mathrm{~b})$. Thus, DzLAP1 might play an important role in this process and $L A P 1$ may be associated with the early stages of ripening. In contrast, $L A P-N \mathrm{~s}$ in other plant species are constitutively expressed in all organs [34, 43]. We compared LAP expression during tomato fruit ripening and found that the $L A P-A$ levels were slightly lower at the breaker or ethylene-producing stages than they were in mature green fruit (Supplementary Fig. S2a). Tomato $L A P-N$ is constitutively expressed at all fruit developmental stages (Supplementary Fig. S2b). Therefore, LAPs are not implicated in tomato fruit development or ripening.

Cys-Gly dipeptidase activity was observed in crude durian fruit extract (Supplementary Fig. S3) and in coinfiltrated $\mathrm{N}$. benthamiana leaves overexpressing DzLAP1 (Fig. 4). Cys-Gly hydrolytic activity was higher 
in midripe than unripe durian pulp extracts (Supplementary Fig. S3). This finding was consistent with DzLAP1 upregulation at the midripe stage (Fig. 3a). Thus, CysGly dipeptidase was functional in planta. The observed Cys-Gly dipeptidase activity of DzLAP1 in planta upholds our aforementioned hypothesis and suggests that the Cys generated by Cys-Gly hydrolysis is converted into sulphur volatiles contributing to the malodour of ripening durian fruit. Hence, the $\gamma$-glutamyl cycle is essential for recycling GSH and its amino acid constituents and for durian fruit ripening. Nevertheless, an alternative pathway to GSH recycling has been suggested in other plants. In ripening tomato fruit, the oxidised glutathione (GSSG)-catabolising enzyme $\gamma$-glutamyl transpeptidase (GGT) plays a major role in glutathione degradation that releases Cys-Gly and Glu [44]. In Arabidopsis, an increased GSH content and a drop in Cys-Gly content were observed in the ggt1 knockout line when compared with those of wild type plants [45]. Unlike tomato and Arabidopsis, however, durian fruit is rich in sulphur. For this reason, $\gamma$-glutamyl cycle in durian might have evolved to be more active during ripening.

An in vitro biochemical assay of rDzLAP1 (Fig. 5) disclosed that LAPs have $\mathrm{pH}$ optima in the range of 8.011.0 and metal ion dependency [29, 46, 47]. DzLAP1 has high catalytic efficiency $\left(k_{\text {cat }} / \mathrm{K}_{\mathrm{m}}\right)$ for Cys-Gly $\left(\mathrm{K}_{\mathrm{m}}=1.6\right.$ $\mathrm{mM})$. Therefore, DzLAP1 is a metalloenzyme and a CysGly dipeptidase. The aforementioned $K_{m}$ resembles those for other Cys-Gly peptidases such as AtLAP1 [15], yeast Dug1p [17], and bacterial TdLAP [14] all of which were $\leq 1.3 \mathrm{mM}$. Thus, the affinity of LAP for Cys-Gly corresponds to the millimolar physiological GSH concentration range in living cells $[48,49]$. Durian is more abundant in GSH than many other fruits and vegetables $[8,50]$. For this reason, the cellular GSH level in durian should be higher than the general physiological concentration of this substance and Cys-Gly dipeptidases have highly conserved activity across species. As for other degradable $\alpha$-linked dipeptides, DzLAP1 could not hydrolyse $\gamma$-Glu-Cys-Gly (Table 1 ). Consequently, this enzyme might have specificity for $\alpha$-peptide bonds. However, earlier studies did not investigate the affinities of LAPs for $\gamma$-linked dipeptides.

Subcellular protein localisation can elucidate the correlations between the native functions and the physiological substrates of an enzyme. DzLAP1 is a dual-target protein in the chloroplasts and the cytosol (Fig. 6). However, it harbours a plastidial transit peptide sequence. DzLAP1 transcripts may have an alternative codon to initiate ribosomal translation that bypasses the first start codon [34] and/or forms secondary RNA structures in the sequences adjacent to it [51]. Delta-2isopentenyl pyrophosphate:tRNA isopentenyl transferase (MOD5) is encoded by a single gene, has two translational initiation sites, and is localised to the mitochondria, cytosol, and nucleus [52]. Plastidial DzLAP1 may recycle protein and perform other tasks. As chloroplasts participate in cellular metabolism, they may respond to various stressors [53]. The present study did not clarify the functions of plastidial DzLAP1. However, we propose that, like AtLAPs, it is a molecular chaperone preventing misfolded protein accumulation and other adverse effects [36]. Partial DzLAP1 localisation to the chloroplasts enhances its chaperone and/or protease activity in specific suborganellar compartments. Similar observations were reported for CRP-like protein (Clp) and filamentous temperature-sensitive protein (FtsH). These are major conserved ATP-dependent chaperone and degradative proteases in the stroma and on the thylakoid membranes, respectively [54]. Further experimentation is needed to confirm the role of DzLAP1 in the plastids during fruit ripening.

As Cys-Gly has pro-oxidant activity, its concentration must be regulated. Cys-Gly promotes the formation of reactive oxygen species (ROS) such as hydrogen peroxide and superoxide anion in the presence of certain metal ions [55]. The next step is the oxidation of highly reduced thiols such as GSH [56]. Cytosolic localisation and the enzyme kinetics of DzLAP1 suggest that it hydrolyses Cys-Gly in the cytoplasmic $\gamma$-glutamyl cycle and controls cytosolic Cys-Gly levels. Cys-Gly may also be a substrate for cytosolic DzLAP1 in vivo. In this manner, DzLAP1 regulates Cys-Gly concentration. As $D z L A P 1$ is localised to the cytosol and expressed where ethylene and sulphur volatiles accumulate, it might participate in durian fruit ripening. In fact, the slightly alkaline $\mathrm{pH}$ of the cytoplasm [57] and the chloroplast stroma $[58,59]$ is conducive to DzLAP1 activity.

DzLAP1 and the LAP-N of Arabidopsis and Solanaceae all have similar catalytic, substrate, and metal ionbinding residues. However, DzLAP1 expression differs from those of the latter genes. Durian accumulates high levels of sulphur volatiles that impart a strong flavour and unique odour to the fruit. However, the levels of these thiols must be tightly controlled. Expression of the genes encoding sulphur-metabolising enzymes must be regulated during fruit ripening. The DzLAP1 promoter region may have been modified to produce the optimal DzLAP1 content, limit the amount of Cys-Gly, catalyse Cys recycling, and generate sulphur volatiles and ethylene during fruit ripening. A similar finding was reported for durian-specific upregulation of the methionine $\gamma$ lyase gene [5]. The latter is responsible for sulphur volatile production in plants and bacteria [60, 61]. An isoform of this enzyme associated with fruit ripening has been identified [5]. Figure 7 is a schematic diagram summarising the putative functions of DzLAP1 in durian fruit pulp cytoplasm and chloroplasts. 


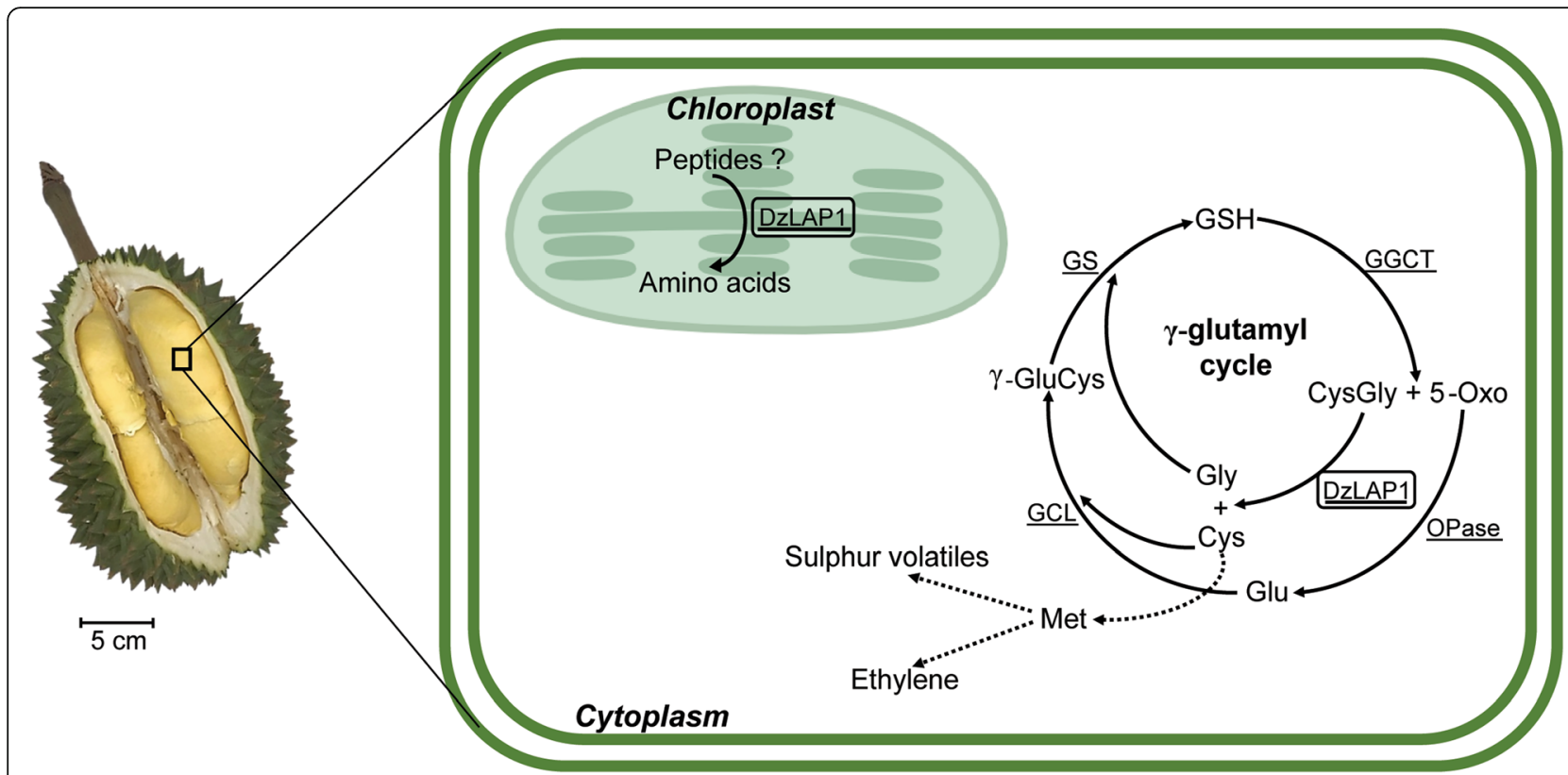

Fig. 7 Schematic representation of putative DzLAP1 functions in durian fruit pulp cytosol and chloroplast. DzLAP1 resides in both the chloroplast and the cytoplasm in the $\gamma$-glutamyl cycle (boxes). Broken lines indicate that at least one reaction is involved. All enzymes are underlined. DzLAP1: leucylaminopeptidase1; GGCT: Y-glutamylcyclotransferase; OPase: oxoprolinase; GCL: glutamate cysteine ligase; GS: GSH synthase; 5-Oxo: 5-oxoproline

\section{Conclusions}

Based on durian cultivar Musang King genomic data, we identified and characterised the LAP- $\mathrm{N}$ gene encoding leucylaminopeptidase (LAP). This enzyme is highly expressed in durian fruit pulp and was designated $D z L A P 1$. We established that DzLAP1 is active in the early stages of durian fruit ripening. However, it is not cultivar-dependent and may not be responsible for the fact that ripe Chanee durian fruit has a stronger odour than ripe Monthong durian fruit. An in planta assay in Nicotiana benthamiana leaves demonstrated Cys-Gly dipeptidase activity. The enzyme kinetics and subcellular localisation of DzLAP1 indicate that it has in vivo CysGly dipeptidase activity. Its presence in the cytosol suggests that it participates in the $\gamma$-glutamyl cycle and is adjacent to intracellular ethylene and sulphur volatile production sites. The plastidial DzLAP1 isoform may participate in protein turnover and/or protection. The present study partially elucidated the mechanisms of sulphur metabolism in plant tissues accumulating high levels of sulphur volatiles.

\section{Methods}

\section{Plant materials and growth conditions}

Mature durian fruit were obtained from two different commercial orchards in Thailand. Chanee fruit were harvested at $95 \mathrm{~d}$ after anthesis from a commercial orchard $\left(12^{\circ} 09^{\prime} 56.6^{\prime \prime} \mathrm{N} 102^{\circ} 41^{\prime} 13.1^{\prime \prime} \mathrm{E}\right)$ in Trat Province in early April 2017. The samples were maintained at room temperature $\left(30^{\circ} \mathrm{C}\right)$ before being peeled on days 1,2 , and 4 (unripe, midripe, and ripe postharvest stages, respectively). Monthong fruit were harvested at day 105 after anthesis from a commercial orchard $\left(12^{\circ} 40^{\prime} 39.2^{\prime \prime} \mathrm{N}\right.$ $102^{\circ} 05^{\prime} 35.2^{\prime \prime E}$ ) in Chanthaburi Province. Monthong served as a representative sample for gene expression analysis. Its three different ripening stages were also evaluated but their timings (days) slightly differed from those of Chanee. Unripe, midripe, and ripe Monthong fruit samples were peeled and analysed at $1 \mathrm{~d}, 3 \mathrm{~d}$, and 5 $\mathrm{d}$, respectively, after storage at room temperature [6]. No special permission was necessary to collect such samples. The collection of plant materials complies with national and international guidelines.

To investigate the association between DzLAP1 and durian fruit ripening, unripe Monthong samples were treated either with ethephon or 1-methylcyclopropene (1-MCP). These synthetic phytohormones have opposite modes of action. Ethephon is converted to ethylene which enhances ripening. In contrast, 1-MCP is an ethylene antagonist and delays ripening. The treated samples were compared with controls naturally ripened according to the method of Khaksar et al. [6]. Three biological replicates were used and each comprised a single durian fruit harvested from a separate tree.

Crude extract from durian pulp was used to determine Cys-Gly dipeptidase activity. Durian cultivar Chanee was obtained from a local market in Nonthaburi Province, Thailand. Postharvest samples were collected at the 
unripe and midripe stages. Three biological replicates were used and each consisted of a single lobe harvested from a separate durian fruit.

Nicotiana benthamiana plants were raised for agroinfiltration. Seeds were sown on peat moss and the seedlings were grown at $25^{\circ} \mathrm{C}$ under a $16 \mathrm{~h} / 8 \mathrm{~h}$ light/dark photoperiod and $4500 \mathrm{~lx}$ (artificial light). Two-week-old plants were individually transplanted to pots and raised under the same conditions for another 2 wks.

\section{Phylogenetic analysis and putative LAP identification in durian fruit}

The protein sequences of LAPs harbouring Cys-Gly dipeptidase activity in Treponema denticola (accession no. WP_010698434.1) [14] and Arabidopsis thaliana (AtLAP1 and AtLAP3; accession nos. P30184.1 and Q8RX72.1, respectively) [15] served as queries for a BLAST search against the $D$. zibethinus cultivar Musang King NCBI database. The MaGenDB database [62] confirmed $D z L A P$ isoforms.

To establish the phylogenetic relationships among LAPs, the amino acid sequences of the putative DzLAPs and other LAPs deposited in NCBI were subjected to ClustalW multiple alignment. A neighbour joining (NJ) tree was created with MEGA v. 7 [63] using 1000 bootstrap replicates.

\section{Determination of tissue-specific DzLAP1 expression}

A search of the DzLAPs against the genomic data for durian cultivar Musang King disclosed two candidate genes (accession nos. XM_022894525.1 (LOC111299369) and XM_022874012.1 (LOC111284913)) annotated as DzLAP1like and named DzLAP1_MK and DzLAP2_MK, respectively. Attention was directed to the durian fruit pulp as it accumulated several sulphur volatiles. DzLAP1 expression was analysed in silico in various fruit tissues. To compare relative $D z L A P$ expression in different tissues, normalised total read counts (RCs) derived from Illumina reads were obtained from the Sequence Read Archive (SRA) resource and processed according to the method of Khaksar et al. [6]. RNA-seq data were obtained for SRX3188225 (root), SRX3188222 (stem), SRX3188226 (leaf), and SRX3188223 (aril/pulp) [5]. A heatmap based on the RCs was constructed using MetaboAnalyst v. 4.0 [64].

\section{Gene expression analysis by qRT-PCR}

Total RNA was isolated from Chanee and Monthong durian cultivar pulps with PureLink ${ }^{\circ}$ plant RNA reagent (Thermo Fisher Scientific, Waltham, MA, USA) following the manufacturer's instructions. DNase-treated RNA sample quantity and integrity were assessed. Approximately $1 \mu \mathrm{g}$ total RNA was reverse-transcribed to cDNA with a RevertAid first-strand cDNA synthesis kit (Thermo Fisher Scientific, Waltham, MA, USA). Gene- specific primers listed in Supplementary Table S1. The qRT-PCR elucidated DzLAP1 expression in unripe, midripe, and ripe durian fruit. The reactions were performed in $10 \mu \mathrm{L}$ total volume in a 96-well PCR plate. The cDNA and primers were combined with Luna universal qPCR master mix (New England Biolabs, Ipswich, MA, USA). PCR was run in a CFX Connect ${ }^{\text {Tw }}$ real-time PCR detection system coupled to CFX Manager ${ }^{\mathrm{man}}$ (Bio-Rad Laboratories, Hercules, CA, USA). Single amplicon production was verified by melting curve analysis. Relative gene expression levels were calculated by the $2^{-\Delta \Delta C t}$ method [65] based on the cycle threshold ( $\mathrm{Ct})$ of the gene relative to the reference gene elongation factor 1 alpha $(E F-1 \alpha)$. There were three independent biological replicates in the qRT-PCR. Gene expression analyses were also conducted on the ethephon- and 1-MCPtreated samples and the naturally un/ripened samples (controls).

\section{In planta Cys-Gly dipeptidase activity assay}

To determine Cys-Gly dipeptidase activity in durian fruit pulp, crude enzyme was extracted from it at the unripe and midripe stages. Pulp samples were separately collected, frozen in liquid nitrogen, and pulverised in the MM400 mixer mill (Retsch GmbH, Haan, Germany) at $30 \mathrm{~Hz}$ for $1 \mathrm{~min}$. Then $250 \mathrm{mg}$ of each sample was dissolved in $2.5 \mathrm{~mL}$ lysis buffer $\left(50 \mathrm{mM} \mathrm{K}_{3} \mathrm{PO}_{4}, \mathrm{pH} 8.0\right)$ and gently mixed at $4{ }^{\circ} \mathrm{C}$ for $1 \mathrm{~h}$. The samples were centrifuged at $14,000 \times g$ and $4{ }^{\circ} \mathrm{C}$ for $5 \mathrm{~min}$ and the supernatant was collected. An enzyme activity assay was performed by incubating durian fruit pulp extract with $20 \mathrm{mM}$ Cys-Gly in reaction buffer $\left(50 \mathrm{mM} \mathrm{K}_{3} \mathrm{PO}_{4}\right.$ buffer $(\mathrm{pH} 8.0)+1 \mathrm{mM} \mathrm{MgCl} 2$ ) at $30 \mathrm{~min}, 1 \mathrm{~h}$, and $3 \mathrm{~h}$. The enzyme activity was measured by a modified acidic ninhydrin method [39]. Briefly, $50 \mu \mathrm{L}$ of each enzyme reaction system was terminated with $50 \mu \mathrm{L}$ glacial acetic acid followed by $50 \mu \mathrm{L}$ acidic ninhydrin solution $(250 \mathrm{mg}$ ninhydrin in $6 \mathrm{~mL}$ glacial acetic acid $+4 \mathrm{~mL} \mathrm{HCl}$ ), boiled for $9 \mathrm{~min}$, and cooled with tap water. The pink endpoint indicated the reaction between the released Cys and ninhydrin under acidic conditions. Colour intensity was measured spectrophotometrically at $\mathrm{A}_{560}$ (BioTex, Winooski, VT, USA). Three independent biological replicates were used.

In planta Cys-Gly dipeptidase activity was also investigated. Full-length DzLAP1 was amplified with Phusion Hot Start II high-fidelity DNA polymerase (Thermo Fisher Scientific, Waltham, MA, USA) using Chanee cDNA as a template. The gene-specific primers (excluding the stop codon) listed in Supplementary Table S1 were used in the PCR. The PCR product was cloned into a $\mathrm{pCR}^{\mathrm{m}} 8 / \mathrm{GW} / \mathrm{TOPO}^{\circ} \mathrm{TA}$ cloning vector (Invitrogen, Carlsbad, CA, USA) and generated pTOPO-DzLAP1. The latter was then sequenced. DzLAP1 was transferred 
to the pEAQ3 destination vector and fused at the $C$-terminal with $6 \times$ His [66] via Gateway ${ }^{\circ}$ LR Clonase ${ }^{\circ}$ II (Invitrogen, Carlsbad, CA, USA). The pEAQ-DzLAP1 product was transformed into Agrobacterium tumefaciens GV3101 by electroporation.

A. tumefaciens bearing the DzLAP1-6xHis or the empty pEAQ vector (control) was infiltrated into $4 \mathrm{wk}$. plants. Briefly, cells from each culture were washed and suspended in MM buffer (10 mM MES buffer $+10 \mathrm{mM}$ $\mathrm{MgCl}_{2} ; \mathrm{pH}$ 5.6). The cell suspension was adjusted at $\mathrm{A}_{600}$ to $\mathrm{OD}=0.6$. Acetosyringone was added to make up $200 \mu \mathrm{M}$ final concentration and the suspension was kept in the dark at $30^{\circ} \mathrm{C}$ for $2 \mathrm{~h}$ before infiltration. At day 3 after agroinfiltration, the leaves were infiltrated with 15 $\mathrm{mM}$ Cys-Gly, incubated for $1 \mathrm{~h}$ [67], freeze-dried, and kept in a dry place at $30^{\circ} \mathrm{C}$ until subsequent metabolite analysis by HPLC. To measure the foliar Cys-Gly levels, the co-infiltrated leaves were pulverised in the MM400 mixer mill (Retsch $\mathrm{GmbH}$, Haan, Germany) at $30 \mathrm{~Hz}$ for $1 \mathrm{~min}$. Each sample was suspended in $0.1 \mathrm{M} \mathrm{HCl}$ extraction buffer at $1 \mathrm{mg} / 50 \mu \mathrm{L}$. Then, $10 \mathrm{mMN} N$-acetylcysteine (internal standard) was added and mixed by shaking at $250 \mathrm{rpm}$ and $37^{\circ} \mathrm{C}$ for $2.5 \mathrm{~h}$. The samples were centrifuged at $14,000 \times g$ and $30^{\circ} \mathrm{C}$ for $5 \mathrm{~min}$. The soluble fraction was transferred to a new microcentrifuge tube, combined with acetonitrile (1:1), and centrifuged at 14 , $000 \times g$ and $30^{\circ} \mathrm{C}$ for $5 \mathrm{~min}$. The pellet was removed and the supernatant was dried with a CentriVap benchtop vacuum concentrator (Labconco Corp., Kansas City, MO, USA). The dried samples were re-dissolved in $200 \mu \mathrm{L}$ deionised $\mathrm{H}_{2} \mathrm{O}$, passed through a $0.22-\mu \mathrm{m}$ syringe filter, and subjected to HPLC analysis. Ten microlitres of each sample was injected into a C18 column $(250 \mathrm{~mm} \times$ $4.6 \mathrm{~mm}$; Phenomenex, Torrance, CA, USA) using acetonitrile $(5 \%)$ in $2 \%$ perchloric acid as a mobile phase. The flow rate was $1 \mathrm{~mL} / \mathrm{min}$ and the temperature was $40^{\circ} \mathrm{C}$. The Cys-Gly peak was detected at $210 \mathrm{~nm}$ [15]. Three independent biological replicates were used and each consisted of a separate leaf.

\section{DzLAP1 cloning and expression in Escherichia coli}

The putative DzLAP1 was amplified with Phusion Hot Start II DNA polymerase (Thermo Fisher Scientific, Waltham, MA, USA) and midripe Chanee durian cultivar cDNA served as a template. The PCR temperature profile was as follows: initial denaturation at $98^{\circ} \mathrm{C}$ for $30 \mathrm{~s} ; 30$ cycles of $98^{\circ} \mathrm{C}$ for $10 \mathrm{~s} ; 57^{\circ} \mathrm{C}$ for $10 \mathrm{~s} ; 72^{\circ} \mathrm{C}$ for $1 \mathrm{~min}$; and a final extension at $72^{\circ} \mathrm{C}$ for $5 \mathrm{~min}$. Genespecific forward and reverse primers were designed according to the DzLAP1_MK sequence (Supplementary Table S1). The signal sequences predicted by the ChloroP1.1 and TargetP servers were excluded. The putative DzLAP1 PCR product was excised with restriction enzymes (FastDigest ${ }^{\mathrm{m}}$; Thermo Fisher Scientific,
Waltham, MA, USA) and cloned into a pET21b vector (Merck KGaA, Darmstadt, Germany). The product was pET21b-DzLAP1 in-frame with 18 nucleotides encoding $6 \times$ His residues at the $C$-terminus. It was transformed into E. coli TOP10 (K2500-20; Invitrogen, Carlsbad, CA, USA). Bacterial colonies were raised on LB agar supplemented with $1 \mathrm{mg} \mathrm{mL}^{-1}$ ampicillin and analysed by colony PCR. The nucleotide sequences of the positive clones were verified by 1st BASE DNA sequencing.

\section{Recombinant DzLAP1 (rDzLAP1) production and purification}

The pET21b-DzLAP1 was transformed into the T7 host E. coli SoluBL21 (DE3). Cells harbouring the recombinant plasmid were incubated overnight in LB broth supplemented with $1 \mathrm{mg} \mathrm{mL}^{-1}$ ampicillin. The starter culture was inoculated into fresh LB broth supplemented with $1 \mathrm{mg} \mathrm{mL}^{-1}$ ampicillin and incubated at $37^{\circ} \mathrm{C}$ with shaking at $250 \mathrm{rpm}$ until $\mathrm{OD}_{600}=0.4-0.5$. The rDzLAP1 was generated by induction with $1 \mathrm{mM}$ isopropyl $\beta-D-1$ thiogalactopyranoside (IPTG) at $30^{\circ} \mathrm{C}$ and shaking at $250 \mathrm{rpm}$ for $17 \mathrm{~h}$. The cells were harvested by centrifugation at $5000 \times g$ and $37^{\circ} \mathrm{C}$ for $10 \mathrm{~min}$, suspended in buffer A (25 mM K K $\mathrm{PO}_{4}$ buffer $\left.+0.3 \mathrm{M} \mathrm{NaCl} ; \mathrm{pH} 7.2\right)$, and lysed by ultrasonication. Soluble intracellular proteins were collected by centrifugation at $7500 \times g$ and $4{ }^{\circ} \mathrm{C}$ for $30 \mathrm{~min}$, analysed by western blot (6x His epitope tag antibody; Thermo Fisher Scientific, Waltham, MA, USA), and stored at $4{ }^{\circ} \mathrm{C}$ until purification.

The crude extract was loaded onto a HisTrap ${ }^{\text {Tx }}$ column (Merck, Darmstadt, GER) pre-equilibrated with buffer A. The column was washed with excess buffer A and the rDzLAP1 was eluted with buffer B $(25 \mathrm{mM}$ $\mathrm{K}_{3} \mathrm{PO}_{4}$ buffer $+0.3 \mathrm{M} \mathrm{NaCl}+150 \mathrm{mM}$ imidazole; $\mathrm{pH}$ 7.2). The samples were analysed by SDS-PAGE and western blot. The pooled purified rDzLAP1 fraction was dialysed against $25 \mathrm{mM} \mathrm{K}_{3} \mathrm{PO}_{4}$ buffer ( $\mathrm{pH}$ 7.2). The protein concentration was determined by a modified Bradford assay [68]. The reference protein standard was BSA.

\section{Enzymatic rDzLAP1 assay}

The metal ion dependency of rDzLAP1 was evaluated. The enzyme was incubated at $37^{\circ} \mathrm{C}$ for $15 \mathrm{~min}$ with 7.5 $\mathrm{mM}$ Cys-Gly in $25 \mathrm{mM} \mathrm{K}_{3} \mathrm{PO}_{4}$ buffer (pH 7.2) in the presence of $0 \mathrm{mM}$ or $1 \mathrm{mM} \mathrm{Ca}{ }^{2+}, \mathrm{Zn}^{2+}, \mathrm{Mg}^{2+}, \mathrm{Ni}^{2+}$, or $\mathrm{Mn}^{2+}$. The total reaction volume was $50 \mu \mathrm{L}$. Enzyme activity was measured by a modified acidic ninhydrin method [39]. To determine the optimum enzyme $\mathrm{pH}$, $50-\mu \mathrm{L}$ reaction systems were prepared by incubating rDzLAP1 with $7.5 \mathrm{mM}$ Cys-Gly and $1 \mathrm{mM} \mathrm{Mg}^{2+}$ at various pH (acetate buffer, $\mathrm{pH} 4-6$; phosphate buffer, $\mathrm{pH} 6-$ 8; Tris-HCl buffer, $\mathrm{pH}$ 8-9.5; glycine- $\mathrm{NaOH}$ buffer, $\mathrm{pH}$ 
9.5-11) at $37^{\circ} \mathrm{C}$ for $15 \mathrm{~min}$. Maximum enzyme activity was defined as $100 \%$ relative activity.

To assess enzyme kinetics, $3.5 \mu \mathrm{g}$ purified rDzLAP1 was incubated with 0-10 mM Cys-Gly, $\gamma$-Glu-Cys, GSH, Met-Gly, or Leu-Gly in the presence of $1 \mathrm{mM} \mathrm{MgCl}_{2}$ in $25 \mathrm{mM} \mathrm{K}{ }_{3} \mathrm{PO}_{4}$ buffer $\left(\mathrm{pH} \mathrm{8.0)}\right.$ at $37^{\circ} \mathrm{C}$ for a specific length of time. The reactions were terminated with 0.13 $\mathrm{N} \mathrm{HCl}$. For $\gamma$-Glu-Cys and GSH, the reactions were evaluated by a modified acidic ninhydrin assay. For Cys-Gly, Met-Gly, and Leu-Gly, the reactions were analysed by monitoring the decrease in absorbance of the free peptides at $A_{230}$, with minor modifications [69]. Enzyme kinetics were measured with OriginPro 2017 (OriginLab Corp., Northampton, MA, USA).

\section{Subcellular localisation}

Full-length DzLAP1 was amplified and cloned into a $\mathrm{pCR}^{\mathrm{m}} 8 / \mathrm{GW} / \mathrm{TOPO}^{\circ}$ TA vector (Invitrogen, Carlsbad, CA, USA) according to the in planta Cys-Gly dipeptidase activity assay. The pTOPO-DzLAP1 product was then sequenced. The DzLAP1 was transferred to the pGWB5 destination vector and fused at the $C$-terminal with green fluorescent protein (GFP) [70] via Gateway ${ }^{\circ}$ LR Clonase ${ }^{\circ}$ II (Invitrogen, Carlsbad, CA, USA). The pGWB5-DzLAP1 product was transformed into A. tumefaciens GV3101 by electroporation.

Agrobacterium tumefaciens bearing the DzLAP1-GFP construct and $A$. tumefaciens with the silencing suppressor $p 19$ gene [71] were co-infiltrated into 4-wk plants as previously described, with some modifications. Briefly, cells from each culture were washed and suspended in MM buffer (10 mM MES buffer $+10 \mathrm{mM} \mathrm{MgCl}_{2}$; $\mathrm{pH}$ 5.6). Cell suspensions harbouring $D z L A P 1$ and $p 19$ were adjusted at $\mathrm{A}_{600}$ to $\mathrm{OD}=0.8$ and 0.6 , respectively, and combined in a 1:1 ratio. Acetosyringone was added to the mixture to a final concentration of $200 \mu \mathrm{M}$ and the suspension was maintained in the dark at room temperature for $2 \mathrm{~h}$ before infiltration. At day 3 after infiltration, autofluorescence was visualised under a Fluo$V^{\circ} w^{\circ}$ FV10i-DOC confocal laser scanning microscope (Olympus Corp., Tokyo, Japan). GFP, chloroplast autofluorescence, and phase-contrast detection excitation/ emission were recorded at $473 / 510 \mathrm{~nm}, 559 / 600 \mathrm{~nm}$, and $559 / 600 \mathrm{~nm}$, respectively.

\section{Statistical analysis}

All data were analysed with SPSS Statistics ${ }^{\circ}$ v. 22.0 (IBM Corp., Armonk, NY, USA). One-way ANOVA identified significant differences among mean enzyme activity levels in the absence and presence of metal ions. CysGly dipeptidase gene expression levels and enzyme activity at various ripening stages and in response to different ripening regulators were analysed by Tukey's
HSD multiple comparisons test $(p<0.05)$. Student's $t$ test $(p<0.05)$ identified significant differences between $N$. benthamiana leaves overexpressing DzLAP1 and the control in terms of in planta Cys-Gly dipeptidase activity.

\section{Supplementary Information}

The online version contains supplementary material available at https://doi. org/10.1186/s12870-021-02845-6.

Additional file 1: Supplementary Table S1. Primers used in the present study. Restriction sites are underlined.

Additional file 2: Supplementary Fig. S1. Tissue-specific DzLAP expression profiles in Musang King durian fruit pulp. DzLAP1_MK and DZLAP2_MK expression levels in fruit pulp, stem, leaf, and root were analysed by RNA-seq. Red: higher gene expression level; blue: lower gene expression level. Data were sum-normalised, log-transformed, and autoscaled.

Additional file 3: Supplementary Fig. S2. Relative $\angle A P-A(a)$ and $L A P$ $N(b)$ expression at various developmental stages of tomato fruit. LAP-A (Solyc12g010020) (a) and LAP-N (Solyc12g010040) (b) expression levels in tomato (Solanum lycopersicum) were determined from Illumina-based and RPKM-normalised data [72] and represented in Tomato eFP Browser v. 2.0. Mature green, breaker, and breaker $+10 \mathrm{~d}$ tomato fruit ripening stages were compared.

Additional file 4: Supplementary Fig. S3. Determination of Cys-Gly dipeptidase activity in durian pulp extract. Twenty-microlitre unripe (black bars) and midripe (white bars) durian fruit extracts were incubated with $20 \mathrm{mM}$ Cys-Gly in $50 \mathrm{mM} \mathrm{K}_{3} \mathrm{PO}_{4}$ buffer ( $\mathrm{pH} \mathrm{8.0)}$ in the presence of $1 \mathrm{mM}$ $\mathrm{Mg}^{2+}$ at $37^{\circ} \mathrm{C}$ for $30 \mathrm{~min}, 1 \mathrm{~h}$, and $3 \mathrm{~h}$. The total reaction volume was $50 \mu \mathrm{L}$. Enzyme activity was measured spectrophotometrically by a modified acidic ninhydrin method at $560 \mathrm{~nm}\left(\mathrm{~A}_{560}\right)$. Bars: means \pm standard deviation (SD) of three independent biological replicates. Different letters indicate significant differences according to Tukey's HSD multiple-range test $(p<0.05)$.

\section{Abbreviations}

GSH: Glutathione; $\gamma$-EC: $\gamma$-glutamylcysteine; Cys-Gly: Cysteinylglycine; Cys: Cysteine; LAP: Leucylaminopeptidase; DzLAP: Durio zibethinus L. leucylaminopeptidase gene

\section{Acknowledgements}

The authors thank Kittiya Tantisuwanichkul and Pinnapat Pinsorn for providing the durian CDNA samples, Drs. Gholamreza Khaksar and Lalida Sangpong for their assistance with the RNA-seq data analysis, Tsuyoshi Nakagawa of Shimane University, Shimane, Japan, for providing the Gateway ${ }^{\circledR}$ expression vector pGWB5, Sophien Kamoun of Sainsbury Laboratory, Norwich, Norfolk, UK for providing A. tumefaciens GV3101 harbouring pJL3:p19, and Plant Bioscience Ltd. (Norwich, UK) for supplying the PEAQ vector.

\section{Authors' contributions}

S.S. conceived the study. P.P. and S.S. designed the experiments. P.P. conducted the experiments. P.P. and S.S. analysed the data and prepared the manuscript. All authors have read and approved the manuscript.

\section{Funding}

This study was supported by the Thailand Research Fund (No. RSA6080021), Chulalongkorn University (No. GRU 6203023003-1 to S.S.). P. P received the Second Century Fund (C2F) Postdoctoral Fellowship of Chulalongkorn University. The funding bodies were not involved in the design of the study and plant sample collection, data analyses, data interpretation, and writing of the manuscript.

Availability of data and materials

The datasets used and/or analysed during the current study are available from the corresponding author on reasonable request. 


\section{Ethics approval and consent to participate}

Not applicable.

\section{Consent for publication}

Not applicable.

\section{Competing interests}

The authors declare that they have no competing interests.

Received: 21 April 2020 Accepted: 21 January 2021

Published online: 01 February 2021

\section{References}

1. Charoenkiatkul S, Thiyajai P, Judprasong K. Nutrients and bioactive compounds in popular and indigenous durian (Durio zibethinus murr.). Food Chem. 2016;193:181-6.

2. Arancibia-Avila P, Toledo F, Park Y-S, Jung S-T, Kang S-G, Heo BG, Lee S-H, Sajewicz M, Kowalska T, Gorinstein S. Antioxidant properties of durian fruit as influenced by ripening. LWT Food Sci Technol. 2008;41:2118-25.

3. Maninang JS, Lizada MCC, Gemma H. Inhibition of aldehyde dehydrogenase enzyme by Durian (Durio zibethinus Murray) fruit extract. Food Chem. 2009; 117:352-5.

4. Haruenkit R, Poovarodom S, Vearasilp S, Namiesnik J, Sliwka-Kaszynska M, Park Y-S, Heo B-G, Cho J-Y, Jang HG, Gorinstein S. Comparison of bioactive compounds, antioxidant and antiproliferative activities of Mon Thong durian during ripening. Food Chem. 2010;118:540-7.

5. Teh BT, Lim K, Yong CH, Ng CCY, Rao SR, Rajasegaran V, Lim WK, Ong CK, Chan K, Cheng VKY. The draft genome of tropical fruit durian (Durio zibethinus). Nat Genet. 2017;49:1633.

6. Khaksar G, Sangchay W, Pinsorn P, Sangpong L, Sirikantaramas S. Genome-wide analysis of the Dof gene family in durian reveals fruit ripening-associated and cultivar-dependent Dof transcription factors. Sci Rep. 2019;9:1-13.

7. Khaksar $\mathrm{G}$, Sirikantaramas $\mathrm{S}$. Auxin response factor $2 \mathrm{~A}$ is part of the regulatory network mediating fruit ripening through auxin-ethylene crosstalk in durian. Front Plant Sci. 2020;11:543747.

8. Pinsorn P, Oikawa A, Watanabe M, Sasaki R, Ngamchuachit P, Hoefgen R, Saito K, Sirikantaramas $S$. Metabolic variation in the pulps of two durian cultivars: unraveling the metabolites that contribute to the flavor. Food Chem. 2018;268:118-25.

9. Martin MN, Saladores PH, Lambert E, Hudson AO, Leustek T. Localization of members of the $\gamma$-glutamyl transpeptidase family identifies sites of glutathione and glutathione s-conjugate hydrolysis. Plant Physiol. 2007;144: 1715-32.

10. Ohkama-Ohtsu N, Oikawa A, Zhao P, Xiang C, Saito K, Oliver DJ. A Yglutamyl transpeptidase-independent pathway of glutathione catabolism to glutamate via 5-oxoproline in Arabidopsis. Plant Physiol. 2008;148:1603-13.

11. Kumar C, lgbaria A, D'autreaux B, Planson AG, Junot C, Godat E, Bachhawat AK, Delaunay-Moisan A, Toledano MB. Glutathione revisited: a vital function in iron metabolism and ancillary role in thiol-redox control. EMBO J. 2011; 30:2044-56.

12. Srikanth CV, Vats P, Bourbouloux A, Delrot S, Bachhawat AK. Multiple cisregulatory elements and the yeast sulphur regulatory network are required for the regulation of the yeast glutathione transporter, Hgt1p. Curr Genet. 2005;47:345-58.

13. Cappiello M, Lazzarotti A, Buono F, Scaloni A, D'ambrosio C, Amodeo P, Méndez BL, Pelosi P, Del Corso A, Mura U. New role for leucyl aminopeptidase in glutathione turnover. Biochem J. 2004;378:35-44.

14. Chu L, Lai Y, Xu X, Eddy S, Yang S, Song L, Kolodrubetz D. A 52-kDa leucyl aminopeptidase from Treponema denticola is a cysteinylglycinase that mediates the second step of glutathione metabolism. J Biol Chem. 2008; 283:19351-8.

15. Kumar S, Kaur A, Chattopadhyay B, Bachhawat AK. Defining the cytosolic pathway of glutathione degradation in Arabidopsis thaliana: role of the ChaC/GCG family of $\gamma$-glutamyl cyclotransferases as glutathione-degrading enzymes and AtLAP1 as the Cys-Gly peptidase. Biochem J. 2015;468:73-85

16. Spackman DH, Smith EL, Brown DM. Leucine aminopeptidase IV. Isolation and properties of the enzyme from swine kidney. J Biol Chem. 1955;212: 255-69.

17. Kaur H, Kumar C, Junot C, Toledano MB, Bachhawat AK. Dug1p is a cys-gly peptidase of the $\gamma$-glutamyl cycle of Saccharomyces cerevisiae and represents a novel family of cys-gly peptidases. J Biol Chem. 2009;284: 14493-502.

18. Carpenter FH, Vahl JM. Leucine aminopeptidase (bovine lens) mechanism of activation by $\mathrm{Mg}^{2+}$ and $\mathrm{Mn}^{2+}$ of the zinc metalloenzyme, amino acid composition, and sulfhydryl content. J Biol Chem. 1973;248: 294-304.

19. McCulloch R, Burke ME, Sherratt DJ. Peptidase activity of Escherichia coli aminopeptidase $\mathrm{A}$ is not required for its role in Xer site-specific recombination. Mol Microbiol. 1994;12:241-51.

20. Charlier D, Kholti A, Huysveld N, Gigot D, Maes D, Thia-Toong T-L, Glansdorff N. Mutational analysis of Escherichia coli PepA, a multifunctional DNAbinding aminopeptidase. J Mol Biol. 2000;302:409-24.

21. Stirling C, Colloms S, Collins J, Szatmari G, Sherratt D. xerB, an Escherichia coli gene required for plasmid ColE1 site-specific recombination, is identical to pepA, encoding aminopeptidase $\mathrm{A}$, a protein with substantial similarity to bovine lens leucine aminopeptidase. EMBO J. 1989:8:1623-7.

22. Colloms SD. Leucyl aminopeptidase PepA. In: Handbook of proteolytic enzymes. San Diego: Elsevier; 2004. p. 905-10.

23. Harris C, Hunte B, Krauss M, Taylor A, Epstein L. Induction of leucine aminopeptidase by interferon-gamma. Identification by protein microsequencing after purification by preparative two-dimensional gel electrophoresis. J Biol Chem. 1992;267:6865-9.

24. Towne CF, York IA, Neijssen J, Karow ML, Murphy AJ, Valenzuela DM, Yancopoulos GD, Neefjes JJ, Rock KL. Leucine aminopeptidase is not essential for trimming peptides in the cytosol or generating epitopes for MHC class I antigen presentation. J Immunol. 2005;175:6605-14.

25. Sharma KK, Kester K. Peptide hydrolysis in lens: role of leucine aminopeptidase, aminopeptidase III, prolyloligopeptidase and acylpeptidehydrolase. Curr Eye Res. 1996;15:363-9.

26. Hildmann T, Ebneth M, Peña-Cortés H, Sánchez-Serrano JJ, Willmitzer L, Prat S. General roles of abscisic and jasmonic acids in gene activation as a result of mechanical wounding. Plant Cell. 1992;4:1157-70.

27. Herbers K, Prat S, Willmitzer L. Functional analysis of a leucine aminopeptidase from Solatium tuberosum L. Planta. 1994;194:230-40.

28. Milligan SB, Gasser CS. Nature and regulation of pistil-expressed genes in tomato. Plant Mol Biol. 1995;28:691-711.

29. Chao WS, Gu Y-Q, Pautot V, Bray EA, Walling LL. Leucine aminopeptidase RNAs, proteins, and activities increase in response to water deficit, salinity, and the wound signals systemin, methyl jasmonate, and abscisic acid. Plant Physiol. 1999;120:979-92.

30. Gu YQ, Walling LL. Specificity of the wound-induced leucine aminopeptidase (LAP-A) of tomato: activity on dipeptide and tripeptide substrates. Eur J Biochem. 2000;267:1178-87.

31. Gu Y-Q, Chao WS, Walling LL. Localization and post-translational processing of the wound-induced leucine aminopeptidase proteins of tomato. J Biol Chem. 1996:271:25880-7.

32. Chao WS, Pautot V, Holzer FM, Walling LL. Leucine aminopeptidases: the ubiquity of LAP-N and the specificity of LAP-A. Planta. 2000;210:563-73.

33. Pautot V, Holzer FM, Chaufaux J, Walling LL. The induction of tomato leucine aminopeptidase genes (LapA) after Pseudomonas syringae pv. tomato infection is primarily a wound response triggered by coronatine. Mol Plant Microbe Interact. 2001;14:214-24.

34. Tu C-J, Park S-Y, Walling LL. Isolation and characterization of the neutral leucine aminopeptidase (LapN) of tomato. Plant Physiol. 2003;132:243-55.

35. Hartl M, Merker H, Schmidt DD, Baldwin IT. Optimized virus-induced gene silencing in Solanum nigrum reveals the defensive function of leucine aminopeptidase against herbivores and the shortcomings of empty vector controls. New Phytol. 2008;179:356-65.

36. Scranton MA, Yee A, Park S-Y, Walling LL. Plant leucine aminopeptidases moonlight as molecular chaperones to alleviate stress-induced damage. J Biol Chem. 2012;287:18408-17.

37. Kim H, Lipscomb WN. Differentiation and identification of the two catalytic metal binding sites in bovine lens leucine aminopeptidase by X-ray crystallography. Proc Nat Acad Sci. 1993;90:5006-10.

38. Dorus S, Wilkin EC, Karr TL. Expansion and functional diversification of a leucyl aminopeptidase family that encodes the major protein constituents of drosophila sperm. BMC Genomics. 2011;12:177.

39. Gaitonde M. A spectrophotometric method for the direct determination of cysteine in the presence of other naturally occurring amino acids. Biochem J. 1967;104:627. 
40. Foyer $\mathrm{CH}$, Noctor $\mathrm{G}$. Redox homeostasis and antioxidant signaling: a metabolic interface between stress perception and physiological responses. Plant Cell. 2005;17:1866-75

41. May MJ, Vernoux T, Leaver C, Montagu MV, Inze D. Glutathione homeostasis in plants: implications for environmental sensing and plant development. J Exp Bot. 1998:49:649-67.

42. Rawlings ND, Barrett AJ. Introduction: metallopeptidases and their clans. In: Handbook of proteolytic enzymes. San Diego: Elsevier; 2004. p. 231-67.

43. Bartling D, Nosek J. Molecular and immunological characterization of leucine aminopeptidase in Arabidopsis thaliana: a new antibody suggests a semi-constitutive regulation of a phylogenetically old enzyme. Plant Sci. 1994;99:199-209.

44. Sorrequieta A, Ferraro G, Boggio SB, Valle EM. Free amino acid production during tomato fruit ripening: a focus on L-glutamate. Amino Acids. 2010;38: 1523-32.

45. Tolin S, Arrigoni G, Trentin AR, Veljovic-Jovanovic S, Pivato M, Zechman B, Masi A. Biochemical and quantitative proteomics investigations in Arabidopsis ggt 1 mutant leaves reveal a role for the gamma-glutamyl cycle in plant's adaptation to environment. Proteomics. 2013;13:2031-45.

46. Mathew Z, Knox TM, Miller CG. Salmonella enterica serovar Typhimurium peptidase B is a leucyl aminopeptidase with specificity for acidic amino acids. J Bacteriol. 2000;182:3383-93.

47. Walling LL. Leucyl aminopeptidase (plant). In: Handbook of proteolytic enzymes. San Diego: Elsevier; 2004. p. 901-5.

48. Fahey R, Brown W, Adams W, Worsham M. Occurrence of glutathione in bacteria. J Bacteriol. 1978;133:1126-9.

49. Koffler BE, Bloem E, Zellnig G, Zechmann B. High resolution imaging of subcellular glutathione concentrations by quantitative immunoelectron microscopy in different leaf areas of Arabidopsis. Micron. 2013;45:119-28.

50. Wierzbicka GT, Hagen TM, Tones DP. Glutathione in food. J Food Compos Anal. 1989;2:327-37.

51. Yogev O, Pines O. Dual targeting of mitochondrial proteins: mechanism, regulation and function. BBA-Biomembranes. 1808;2011:1012-20.

52. Slusher LB, Gillman EC, Martin NC, Hopper AK. mRNA leader length and initiation codon context determine alternative AUG selection for the yeast gene MOD5. Proc Nat Acad Sci. 1991;88:9789-93.

53. Van Aken O, De Clercq I, Ivanova A, Law SR, Van Breusegem F, Millar $\mathrm{AH}$, Whelan J. Mitochondrial and chloroplast stress responses are modulated in distinct touch and chemical inhibition phases. Plant Physiol. 2016;171:2150-65

54. Nishimura K, Kato Y, Sakamoto W. Chloroplast proteases: updates on proteolysis within and across suborganellar compartments. Plant Physiol. 2016;171:2280-93.

55. Del Corso A, Vilardo PG, Cappiello M, Cecconi I, Dal Monte M, Barsacchi D, Mura U. Physiological thiols as promoters of glutathione oxidation and modifying agents in protein s-thiolation. Arch Biochem Biophys. 2002;397:392-8

56. Noctor G, Queval G, Mhamdi A, Chaouch S, Foyer CH. Glutathione. In: The Arabidopsis book, vol. 9: American Society of Plant Biologists; 2011.

57. Martinière A, Bassil E, Jublanc E, Alcon C, Reguera M, Sentenac H, Blumwald E, Paris N. In vivo intracellular pH measurements in tobacco and Arabidopsis reveal an unexpected $\mathrm{pH}$ gradient in the endomembrane system. Plant Cell. 2013:25:4028-43

58. Höhner R, Aboukila A, Kunz H-H, Venema K. Proton gradients and proton-dependent transport processes in the chloroplast. Front Plant Sci. 2016;7:218.

59. Su P-H, Lai Y-H. A reliable and non-destructive method for monitoring the stromal $\mathrm{pH}$ in isolated chloroplasts using a fluorescent $\mathrm{pH}$ probe. Front Plant Sci. 2017:8:2079.

60. Rébeillé F, Jabrin S, Bligny R, Loizeau K, Gambonnet B, Van Wilder V, Douce $\mathrm{R}$, Ravanel S. Methionine catabolism in Arabidopsis cells is initiated by a $\gamma$ cleavage process and leads to s-methylcysteine and isoleucine syntheses. Proc Nat Acad Sci. 2006;103:15687-92

61. Gonda I, Lev S, Bar E, Sikron N, Portnoy V, Davidovich-Rikanati R, Burger J, Schaffer AA, Tadmor YA, Giovannonni JJ. Catabolism of I-methionine in the formation of sulfur and other volatiles in melon (Cucumis melo L.) fruit. Plant J. 2013;74:458-72.

62. Wang D, Fan W, Guo X, Wu K, Zhou S, Chen Z, Li D, Wang K, Zhu Y, Zhou Y. MaGenDB: a functional genomics hub for Malvaceae plants. Nucleic Acids Res. 2020:48:1076-84.
63. Kumar S, Stecher G, Tamura K. MEGA7: molecular evolutionary genetics analysis version 7.0 for bigger datasets. Mol Biol Evol. 2016;33:1870-4.

64. Chong J, Soufan O, Li C, Caraus I, Li S, Bourque G, Wishart DS, Xia J. MetaboAnalyst 4.0: towards more transparent and integrative metabolomics analysis. Nucleic Acids Res. 2018;46:486-94.

65. Schmittgen TD, Livak KJ. Analyzing real-time PCR data by the comparative C T method. Nat Protoc. 2008;3:1101.

66. Peyret $\mathrm{H}$, Lomonossoff GP. The $\mathrm{pEAQ}$ vector series: the easy and quick way to produce recombinant proteins in plants. Plant Mol Biol. 2013;83:51-8.

67. Hellens RP, Allan AC, Friel EN, Bolitho K, Grafton K, Templeton MD, Karunairetnam S, Gleave AP, Laing WA. Transient expression vectors for functional genomics, quantification of promoter activity and RNA silencing in plants. Plant Methods. 2005;1:1-14.

68. Bradford MM. A rapid and sensitive method for the quantitation of microgram quantities of protein utilizing the principle of protein-dye binding. Anal Biochem. 1976;72:248-54.

69. Tombs M, Souter F, Maclagan N. The spectrophotometric determination of protein at $210 \mathrm{mu}$. Biochem J. 1959;73:167.

70. Nakagawa T, Kurose T, Hino T, Tanaka K, Kawamukai M, Niwa Y, Toyooka K, Matsuoka K, Jinbo T, Kimura T. Development of series of gateway binary vectors, $\mathrm{pGWBs}$, for realizing efficient construction of fusion genes for plant transformation. J Biosci Bioeng. 2007:104:34-41.

71. Lindbo JA. High-efficiency protein expression in plants from agroinfection-compatible Tobacco mosaic virusexpression vectors. BMC Biotechnol. 2007;7:52

72. Consortium TG. The tomato genome sequence provides insights into fleshy fruit evolution. Nature. 2012;485:635.

\section{Publisher's Note}

Springer Nature remains neutral with regard to jurisdictional claims in published maps and institutional affiliations.
Ready to submit your research? Choose BMC and benefit from:

- fast, convenient online submission

- thorough peer review by experienced researchers in your field

- rapid publication on acceptance

- support for research data, including large and complex data types

- gold Open Access which fosters wider collaboration and increased citations

- maximum visibility for your research: over 100M website views per year

At $\mathrm{BMC}$, research is always in progress.

Learn more biomedcentral.com/submissions 